\title{
NESTED MODES, ‘QUA’ AND THE INCARNATION
}

\section{ALEXANDER R. PRUSS}

Baylor University

\begin{abstract}
A nested mode ontology allows one to make sense of apparently contradictory Christological claims such as that Christ knows everything and there are some things Christ does not know.
\end{abstract}

\section{INTRODUCTION}

According to traditional Christian doctrine, Christ is God and Christ is human. God knows everything. A human being does not know everything (if only because a human being's finite mind cannot hold all the infinitely many mathematical truths). Thus Christ knows everything and does not know everything, surely a contradiction. Likewise, God always feels infinite joy, while Jesus Christ was tortured to death. Thus, Christ felt infinite joy and yet was tortured to death. A standard response to these apparent contradictions is that Christ qua God feels infinite joy and knows everything, but qua human he was tortured and there are things he does not know. However, this 'qua' not only seems to be an obscure cheat, but it is not clear how it removes the contradiction (Morris, 1987).

The 'qua' move is not a cheat. I will start with a nested mode or trope ontology inspired by Spinoza and Aristotle. Then I will discuss how we would express facts within that ontology in English, and show that very naturally one gets locutions that have a formal structure similar to the Christological case, including that mysterious 'qua'. I will outline the beginning of a semantics for the Christological locutions. Finally, I will discuss the possibility of extending the story outside of the nested mode context, and how one might reconcile the account with divine simplicity. ${ }^{1}$

${ }^{1}$ For an excellent thorough recent discussion of the ways of understanding the Christological 'qua', see Pawl (2015). 


\section{NESTED MODES AND ESSENCES}

Modes are particular instances of properties. They are often called 'tropes' in contemporary metaphysics, but I will use the older term 'mode' so as not to suggest a trope-bundle ontology (what I say may be compatible with a trope-bundle ontology, but does not require it). The accidents of Aristotelian ontology should be seen as modes, and in those Aristotelian ontologies that suppose individual essences, essences are modes as well. And the term 'mode' is found throughout the work of Descartes, Leibniz and Spinoza. Beyond trope theory proper, the qualia of some contemporary philosophies of mind are probably best seen as modes of conscious being or modes of thought.

On a mode ontology, whenever an object satisfies a fundamental unary predicate, it has a corresponding mode. Thus, if 'is negatively charged' is a fundamental unary predicate, and Ellie the electron is spinning, then Ellie has a mode of spin, Ellie's spin. If Pam the positron is also spinning, even if its spin is just like Ellie's, Pam's spin is still something distinct from Ellie's.

There will also be modes corresponding to non-unary predicates. If 'loves' is fundamental, then when Romeo loves Juliet, there is at least one mode of love. There are a number of options here:

(1) There is a single relational mode, which can be denoted either 'Romeo's loving Juliet' or 'Juliet's being loved by Romeo', and both Romeo and Juliet have that mode.

(2) There are two relational modes, Romeo's loving Juliet and Juliet's being loved by Romeo, and Romeo and Juliet have them respectively.

(3) There is only a single relational mode, Romeo's loving Juliet, and Romeo has it.

(4) There is only a single relational mode, Juliet's being loved by Romeo, and Juliet has it.

Given that coming to be loved appears to be a mere Cambridge change, while coming to have a mode appears to be a non-Cambridge change, we have good reason to opt for (3). But perhaps I am wrong about that, and anyway in the case of other predicates other options may be more appropriate.

I leave open whether there are modes corresponding to nonfundamental predications (but see Section 3). 
Now, a central insight in Spinoza's ontology is that modes can nested. Thus, Ellie's spin might be upward, and then assuming the direction of spin is fundamental, Ellie's spin will have its mode of upwardness. In this case, we will say that the upwardness is a remote mode of Ellie while it is presumably an immediate mode of Ellie's spin. Note that this example suggests a promising way of connecting nested mode ontology with theories of determinables. Perhaps whenever $\nu$ is a mode of $\mu$, then $\mu$ corresponds to a determinable while $v$ to its determinate.

In general, we can say that $v$ is a remote mode of $x$ (where $x$ is an individual or a mode) provided that there is a mode $\mu$ such that (a) $\mu$ is distinct from $v$ and $x$ (in Section 6 we will discuss whether something could in be a mode of itself), (b) $\nu$ is a mode of $\mu$ and (c) $\mu$ is a mode of $x$. And an immediate mode of $x$ is a mode of $x$ that is not a remote mode of $x$.

Spinoza, of course, goes overboard on this: he makes everything, with the exception of God, be a mode of something else, and so we ourselves end up being infinitely remote modes of God. But we need not follow him there.

Next, let us introduce an Aristotelian element. One of the modes of an individual is an essence. Being a mode, this is an individual essence: although you and I have humanity as our essences, yours is yours and mine is mine.

We now have a decision point that will be crucial. We could take an essence to be simply yet another immediate mode of an individual. But there is a more daring move possible, one that both has metaphysical benefits and will be crucial to our account of the Incarnation: we could suppose that only essences are immediate modes of individuals.

The main metaphysical benefit of this supposition is that it allows us to give an elegant account of what an essence is. As Fine $(1994,1995)$ has shown, the Aristotelian notion of an essence should not be analyzed in terms of modally essential properties, i.e., properties that an entity could not fail to have. Essences are more explanatorily fundamental than the accidents. ${ }^{2}$ The supposition that essences are the immediate modes of individuals then provides us with an elegant account of essences that highlights this fundamentality. For all other modes of an individual will be modes (immediate or remote) of essences, but it is reasonable to take

${ }^{2}$ For other attempts to account for the fundamentality of essences, see Gorman (2005) and Pruss (forthcoming). 
a mode of $x$, at least when the mode is distinct from $x$, to be dependent on $x$. (How our hypothesis connects with modal notions of essential properties is a question for further investigation.)

Thus, given our supposition, we can give an elegant account of the notions of individual, essence and accident in terms of modes and remoteness. An individual is something that is not a mode of something else. An essence is an immediate mode of an individual. An accident is a remote mode of an individual.

I will henceforth make the supposition that only essences are immediate modes of individuals.

If we combine this supposition with the hypothesis that the nesting of modes corresponds to the determinable-determinate relationship, then we conclude that all our other fundamental properties are determinates of the property corresponding to our essence, presumably our humanity. My believing that the Pythagorean Theorem is true is then a way of my being human, just as being green is a way of having color. This is an attractive way of thinking about ourselves.

\section{TALKING ABOUT NESTED MODES}

Suppose that Sally has a mode of running and her mode of running has a mode of quickness. Then we could correctly say:

(5) Sally is running quickly.

and conclude from this that:

(6) Sally is running.

and

(7) Sally is quick.

But the second conclusion can mislead. For suppose that she is also texting. We had better not conclude from (7) and

(8) Sally is texting

that

(9) Sally is texting quickly.

It is quite clear in our mode ontology why the inference here fails. Sally's quickness is a mode of her running, but perhaps not a mode of her texting. For Sally to be texting quickly, it is not enough that she have 
a quickness and a texting, but she would need a quickness that is a mode of the texting ${ }^{3}$ (assuming, contrary to fact, that texting is fundamental).

Suppose that Sally's texting is slow. Then just as we got to say that she is quick, we get to say that

(10) Sally is slow

(or maybe we prefer the wording: 'Sally is being slow') or even

(11) Sally is not quick.

There is, nonetheless, an air of contradiction between (7) and (10), and even more so between (7) and (11). To clear this up, we might expand on these to say:

(1) Sally is quick qua someone running.

(2) Sally is slow qua someone texting.

(3) Sally is non-quick qua someone texting.

For instance, the last of these says that she is texting, but her texting isn't quick.

Thus, expressing innocent claims about nested modes leads quite naturally to adverbial predications like (5), to apparently contradictory claims like (7), (10) and (11), and finally to 'qua' claims.

Nonetheless, not all sentences of the above sort need correspond so neatly with claims about nested modes. In the above, we assumed that 'is running', 'is texting', 'is slow' and 'is quick' are fundamental. But of course in the case of 'is texting' this is almost surely not so, and the case of the other predicates is also not clear.

There are two possibilities here. If we have an abundant mode ontology, where every correct predication corresponds to a mode, then the above needs no adjustment. But if we have a sparse mode ontology, where only fundamental correct predications correspond to modes, we need to complicate matters. Presumably, non-fundamental claims are grounded in fundamental ones, and the above story will apply in the fundamental cases. Likewise, it is plausible that if we can resolve the apparent contradictions in the cases of fundamental Christological predications, then it should be possible to generalize to the nonfundamental case. There may be difficulties, but apart from the special case of negative predications - which we will discuss in Section 4.4 - we

3 This is the same issue that Geach (1956) famously discusses for 'good': that a basketball player is good and also a golfer does not imply that she is a good golfer, much less a good human being. 
leave those for future research. Thus, from now on, I will simply pretend that all the positive predicates we are concerned with are fundamental.

Finally, a verbal point should be noted. When Sally's running has a mode of quickness, it is correct to say both that Sally's running is quick and that Sally is quick. But sometimes a different predicate is applied in the case of the mode and the individual. For instance, suppose Sally's texting is rife with spelling errors. But we shouldn't say that Sally is rife with spelling errors. In fact, even in the case of running, when we say that Sally is quick and that Sally's running is quick, we are using 'is quick' in two different senses.

The verbal point is particularly apposite when we are talking of modes of the essence in our mode ontology. For instance, when Socrates knows $p$, there is a knowledge-of- $p$ mode, which on this ontology is a mode of Socrates' humanity. In virtue of this knowledge mode, Socrates knows $p$. But it is incorrect to say that Socrates' humanity knows $p$. We do not, in fact, have a convenient way of expressing the predicate that applies to Socrates' humanity in virtue of its possession of the knowledge mode. Perhaps we might say that Socrates' humanity is determined to human knowledge of $p$ or that Socrates' humanity confers knowledge of $p$ on him. It should not, however, surprise us if we do not have readymade terms when we analyze things so finely.

\section{CHRISTOLOGICAL APPLICATION}

\subsection{Basic account}

Suppose now that - as far as we know uniquely - Christ is an individual with two essences: humanity and divinity. And then each of these essences has the kinds of modes proper to it.

When Socrates feels pain, Socrates' essence - his humanity mode has a pain mode. When Christ suffers, his essence of humanity has a pain mode. That Socrates' humanity has a pain mode is sufficient to make it true that Socrates feels pain. That Christ's humanity has a pain mode is sufficient to make it true that he feels pain. 'Christ feels pain' is just as literally true as 'Socrates feels pain', and both statements are true for the same kinds of reasons.

Likewise, just as God the Father has a mode of infinite joy, which is a mode of his divinity, so too Christ's divinity has a mode of infinite joy. And just as the fact that the Father has a divinity with a mode of infinite 
joy makes it true that the Father has infinite joy, so too that Christ has a divinity (the numerically same divinity, according to orthodox Trinitarianism) with a mode of infinite joy makes it true, and true in exactly the same sense, that Christ has infinite joy.

At the crucifixion, it would thus be correct to say:

(1) Christ has infinite joy

(2) Christ is in horrendous pain.

The two claims are no more in conflict than the claims that Sally is quick and Sally is slow.

And just as in Sally's case we removed the appearance of contradiction by saying that she is quick qua running and slow qua texting, here we can say:

(1) Christ has infinite joy qua divine

(2) Christ is in horrendous pain qua human.

There is nothing particularly mysterious about the 'qua' in (17) and (18): it simply indicates which mode - the divine essence or the human essence - the joy and pain modes are respectively modes of.

We could also express (17) and (18) adverbially, though the locutions would sound a little strange:

(1) Christ is infinitely joyfully divine.

(2) Christ is horrendously painfully human.

When only one of Christ's essences is conversationally salient, we can omit the mention of essence, and simply make claims like (15) and (16).

In the case of ordinary human beings, we could always add 'qua human' to attributions of pains, pleasures, and the like. But there would be no point, since only one essence - an essence of humanity - is salient when we talk of an ordinary human being, as an ordinary human being (one can take this as partly stipulative of 'ordinary') has only one essence.

\subsection{Metaphysical truth conditions}

Facts about a nested mode ontology are naturally expressed with qua locutions. When dealing with positive $F$, a metaphysical truth condition (cf. Sider 2011, Section 7.4) for

(3) $x$ is $F$ qua $G$

is something like

(4) has a Gness mode which in turn has an Fness mode. 
As noted at the end of Section 3, 'Fness mode' should be understood loosely: 'Fness mode' need not describe a mode by virtue of which $x$ 's Gness mode is $F$, but rather perhaps a mode by virtue of which $x$ 's Gness mode makes $x$ be $F$.

But of course Scripture and liturgy do not use locutions like (21). Instead, we have simple predications, like that Christ existed before all (created) things or that Christ died on the cross. How do we give metaphysical truth conditions for such predications?

First, some sentences use a predicate that simply expresses the individual's essence. Call these 'essence predicates. ${ }^{4}$ For these, the truth conditions are somewhat trivial: the predicate applies to the individual if and only if the individual has a requisite essence. Thus, the truth condition for 'Christ is human' is simply that Christ has a humanity mode.

Now consider a positive non-essence predicate $F$. Depending on wording and context, there will be two possibilities for a truth condition for

(5) $X$ is $F$,

where $X$ is a term denoting Christ. First, we might have unspecified truth conditions, namely:

(6) $X$ has an essence that has a mode of Fness

or we might have one of the two specified truth conditions:

(7) X’s divine essence has a mode of Fness or

(8) X's human essence has a mode of Fness.

Sometimes the choice of designator $X$ makes clear whether (25) or (26) is appropriate by making either divinity or humanity relevant. If $X$ is 'Jesus', 'the Son of Mary' or the like, then humanity is likely to be relevant, while if $X$ is 'the Son of God', 'the Second Person of the Trinity' or a similar term, then divinity is likely to be relevant. On the other hand, the term 'Christ' does not clearly make one or the other nature relevant.

In the context of a conversation that defers linguistically to Christian orthodoxy, where the interlocutors use language in the way Christian

${ }^{4}$ They are not to be confused with 'essential predicates' in the modal sense, namely those predicates that must apply to an individual if that individual is to exist. 
orthodoxy traditionally does, ${ }^{5}$ the predicate $F$ may itself be an indicator of whether we should adopt the reading in (25) or the one in (26). Divinity is relevant when we speak of Christ creating and humanity when we speak of Christ being born.

But often unspecified truth conditions seem appropriate. A competent speaker can responsibly say of a distant animal that it is running without having to know whether it is a dog or a fox, so that even if the animal is a fox, we perhaps should not say that truth condition is

(9) The animal's vulpine essence has a mode of running but

(10) The animal has an essence that has a mode of running.

Likewise, when wording and context do not make salient a particular essence of Christ, the unspecified reading (24) may well be more appropriate. In theological discussion, liturgy and other specialized contexts, one of the two specified truth conditions for Christological predications may well be appropriate. But in more ordinary contexts, the unspecified truth conditions are likely to often be appropriate. As always with such contextual matters, precise rules are not available.

\subsection{The grammar of 'qua'}

Pawl (2015) classifies 'qua'-based responses to the apparent Christological contradictions on the basis of the role played by the term ' $q u a$ ': it could signal tense, signal a tacit sortal, or modify the subject, predicate or copula. Perhaps surprisingly it is not quite clear how the above account fits into Pawl's classification. On the present account, in the context where Sally's running is salient, all of the following sentences will have the same metaphysical truth condition, namely that Sally's running mode has a quickness mode:

(1) Sally is quick.

(2) Sally is quick qua running.

(3) Sally's running is quick.

(4) Sally is running quickly.

At this point there appears to be a choice point for our theory. Do we take (30) to mean something like (31) or something like (32)? If we go

${ }^{5}$ Which may or may not mean that the interlocutors themselves subscribe to this orthodoxy. They may defer linguistically and then go on to criticize. 
for (31), then it seems that our ' $q u a$ ' modifies the subject, making clear that the subject is Sally's running mode. On the other hand, if we go for (32), then it seems the predicate is being modified. Whereas it seemed that the predicate was simply 'is quick', it really is 'is running quickly. But perhaps this is only an illusion of a choice point. After all, all the four sentences in this context have the same metaphysical truth conditions. Perhaps there is but one fact here that is expressed in four different ways: elliptically in (29), with 'qua' in (30), and then in two grammatically distinct ways in (31) and (32).

We can, however, say something more in terms of Sider's (2011) notion of carving at the joints, if we take the nested mode ontology to be not only a correct ontology, but a correct fundamental ontology. On the nested mode ontology, it is (31) that carves closest to the joints of reality, as the ideology of (31) is precisely that of the nested mode ontology, and so there is a sense in which the present account is a subject-modification account. But if our only purpose is to defend the coherence of the doctrine of the Incarnation, then we do not need to embrace nested mode ontology as the fundamental ontology. One might, for instance, say that while it's true to say that there are nested modes, there is some more fundamental account of nested mode language. In that case, (31) may no longer carve closest to the joints.

\subsection{Negative predications}

In the joy and pain examples of Section 4.1, I made things easy for myself: I considered what were at least at first sight ${ }^{6}$ positive predications. Indeed, one might be unimpressed by the account I gave, since perhaps even an ordinary human could experience great joy and great pain at the same time.

But now consider something which is much more plausibly contradictory. Let $p$ be some proposition that God knows but no human being knows. Then it seems we have:

(1) Christ knows $p$

(2) Christ does not know $p$.

And here the contradiction appears much more blatant.

${ }^{6}$ One might think with Augustine that evil is privation, and hence pain, or at least whatever is responsible for the badness of the pain, is at least partly constituted by the absence of something. 
Now, if there are negative modes, like a mode of ignorance, then there is no special difficulty here. Christ's divinity has a mode of knowledge of $p$ while Christ's humanity has a mode of ignorance of $p$. But it is implausible that for every case where $x$ lacks a positive mode, $x$ has a distinct mode of lacking such a positive mode. That would make each of us not only have infinitely many modes, but modes beyond cardinality. ${ }^{7}$

But of course negative predications also occur in perfectly ordinary nested mode cases. When Sally is running quickly but texting slowly, then she is quick and not quick. She is quick because her mode of running has a mode of quickness, and she is not quick because her mode of texting lacks a mode of quickness. Again, inserting 'qua' will remove the air of contradiction.

Thus, Christ knows $p$ because his divinity has a mode of knowledge of $p$, and Christ does not know $p$ because his humanity lacks any mode of knowledge of $p$. Note that the grounds for which it is correct to say that Christ knows $p$ are just like grounds that make it correct to say that the Father knows $p$ : that there is a mode of knowledge had by the mode of divinity. And just as Socrates may not know $p$, because his humanity lacks a mode of knowledge of $p$, so too Christ's ignorance is grounded in his humanity's lacking a mode of knowledge of $p$.

One might object as follows. The right metaphysical truth conditions for

(3) Socrates knows $p$

are not

(4) Socrates' human essence has a knowledge-of- $p$ mode.

For it is epistemically possible for (35) to be true even if it turns out that Socrates is non-human. Rather, we should take the truth conditions for (35) to be:

(5) Socrates has an essence that has a knowledge-of- $p$ mode. But then

(6) Socrates does not know $p$

${ }^{7} \mathrm{I}$ am at best acquainted with finitely many sets. If for every set $a$ that I am not acquainted with I have a distinct mode of non-acquaintance with $a$, then I will have a mode of non-acquaintance for each set, except for finitely many. And the class of all sets has no cardinality, nor does it gain a cardinality when we take finitely many members away. 
will have as its truth conditions:

(7) Socrates has no essence that has a knowledge-of- $p$ mode.

By parallel, then, in a context where unspecified truth conditions are appropriate, we should say that (34) implies:

(8) Christ has no essence that has a knowledge-of- $p$ mode.

And (40) is false on our account, since God has an essence with a mode of knowledge of $p$, namely his divine essence.

Now, first of all, it is not clear that metaphysical truth conditions have to track what is epistemically open to the individual (Sider 2011, Section 7.4 expressly denies it). It might be epistemically open that tables have no particles in them, but the true metaphysical truth conditions for 'There is a table' might still be that there are particles arranged tablewise. So it is still open to insist that the right metaphysical truth conditions for (35) are given by (36), and hence the metaphysical truth conditions for (38) are:

(9) Socrates' humanity has no knowledge-of- $p$ mode.

That said, it is better if the truth conditions remain closer to being epistemically available to the individual, as was discussed in the case of the distant fox.

But even granting that (37) is the right truth condition for (35), the objection assumes a wide scope $e^{8}$ reading of the negation in (38), namely that (38) denies (35). But one can also take the negation to have narrow scope, in which case the nested mode ontology's truth condition could be:

(10) Socrates has an essence that has no knowledge-of- $p$ mode.

Similarly, when we hear that Sally is not quick, we do not assume that she is nowise quick. Rather, usually there is a contextually relevant attribute and we are being told that she is not quick at that, and even when context does not specify the attribute, we do not assume that she is nowise quick.

We do not normally need to make the narrow-wide scope distinction in the case of attributes like knowledge of $p$, but that is because normally we deal with beings like Socrates that have only one essence, and so there

${ }^{8}$ Or medium wide. Perhaps (39) should be read as committing one to the existence of Socrates, while the widest scope reading of the negation in (38) would not. 
is only one contextually relevant essence that might or might not possess a knowledge-of- $p$ mode. Given the auxiliary premise that Socrates has only one essence, one can indeed derive (39) from the denial of (36), and normally we tacitly accept such premises.

But of course once we start speaking about beings with more than one essence, we need to make a decision on how to read negative sentences. A natural move is to take negations to be narrow scope, unless they are qualified or strengthened in a way that forces a wide scope reading, as in: 'Christ nowise does wrong.'

\section{WITHOUT NESTED MODES}

One may even be able to have the main outlines of the above story without nested modes. Instead of taking

(11) Socrates knows $p$

as grounded in

(12) Socrates' humanity has a knowledge-of- $p$ mode, we could take it as grounded in:

(13) Socrates' humanity is $p$-knowledge-conferring,

where we do not take the application of the predicate 'is $p$-knowledgeconferring' to be grounded in a knowledge-of- $p$ mode. We can understand the predication in (45) in line with our favorite non-trope theory of predication, whether Platonist, conceptualist or nominalist. We still need a commitment to individual essences, but not to any remote modes.

If we proceed in this way, however, we lose the analogy between Christological predications and sentences about Sally's being quick (qua running or qua texting). That loss makes the theory less plausible in a way that perhaps cancels out the benefits of not having to have to nested modes. Nonetheless, an ingredient from the modified theory may be useful in the next section. And even if less plausible, the theory may have a use in showing the coherence of the doctrine of the Incarnation, much in the way that van Inwagen (1995) has used relative identity theory to show the coherence of the doctrine of the Trinity without endorsing relative identities in ordinary cases. 


\section{DIVINE SIMPLICITY}

The above account of Christological predication requires that God have a divine essence, and that this essence in turn have modes. On its face this is incompatible with divine simplicity: it implies something like the essence-accident complexity that is denied by proponents of divine simplicity like Aquinas (1920, I.3.6).

But this is too quick. When we say that God has an essence $\varepsilon$ and the essence has a mode $\mu$, this does not force us to admit three things. For it might be that they are all identical, so that $\operatorname{God}=\varepsilon=\mu$, just as an officer, a doctor and a wife may all be one person. Granted, the mode $\mu$ is a mode of the essence $\varepsilon$, and the essence $\varepsilon$ is an essence of God, but just as one can be one's own enemy, so too perhaps something can be its own mode and its own individual essence. (It won't do to object that the essence is abstract while God is concrete, since modes are best taken to be concrete.)

Consider, after all, a plausible functional characterization of modes: an immediate Fness mode $\mu$ of $x$ is an object $\mu$ such that $\mu$, or at least $x$ and $\mu$ together, ${ }^{9}$ fully grounds $x$ 's being $F$. But when $x$ itself fully grounds $x$ being $F$, then the functional characterization makes $x$ be its own Fness trope. And on the Oppy-Brower-Pruss account of divine simplicity (Oppy 2003; Brower 2008; Pruss 2008), God truthmakes, and hence grounds, all the intrinsic attributes of God. (The question of the extension of that account to non-intrinsic attributes, while indeed a challenge to the proponent of simplicity, is not a special difficulty for our nested mode account of the incarnation.)

Alternately, one might simply posit the identity between God and his essence, as typical proponents of divine simplicity do, and then apply the suggestion of Section 5 so that one can do without nested modes. Or at least without them on the side of the divine essence. Perhaps, for instance, something like trope theory is the right account of predication in the case of creaturely subjects but ostrich nominalism is the right account for God.

9 This option or some further refinement may be needed if we are to leave open an understanding of transsubstantiation on which the modes of bread and wine persist even when there no longer is any bread or wine, but only Christ's body and blood. For in such a case, we probably wouldn't want to say that the bread's persistent whiteness trope grounds the bread's being white, since the bread is presumably not white when it doesn't exist (maybe, though, we could take it to ground the past whiteness of the bread?). 


\section{CONCLUSIONS}

Nested mode facts are naturally expressed with 'qua' sentences such that when the 'qua' clause is left off, some of the sentences will look contradictory. A start of a metaphysical semantics for Christological predication in terms of modes of the human and divine essence can be given.

The account has the very significant advantage that ordinary predicates like 'is sitting' to Christ can apply to Christ for exactly the same reasons that they can apply to us: the subject's human essence has the relevant mode. It is indeed a desideratum on a theory of the incarnation that there be such a uniformity between the application of ordinary creaturely predicates to Christ and to us - Christ is a human being like us, except in sin. In this way, the present account will be superior to property transference accounts like Leftow's (2002) and Stump's (2002) on which ordinary predicates apply to Christ because they apply to a proper part of Christ, say his body and soul composite, since it does not seem that in our own case the ordinary predicates apply to us because they apply to a proper part of us (for a discussion of such property borrowing accounts, see Jeffrey 2014). ${ }^{10}$

\section{REFERENCES}

Aquinas, Thomas. 1920. The Summa Theologica of St. Thomas Aquinas. Trans. the Fathers of the English Dominican Province.

Brower, Jeffrey. 2008. 'Making Sense of Divine Simplicity', Faith and Philosophy, 25: 3-30

Fine, Kit. 1994. 'Essence and Modality', in J. Tomberlin (ed.), Philosophical Perspectives VIII: Logic and Language (Atascadero, CA: Ridgeview), pp. 1-16 Fine, Kit. 1995. 'Senses of Essence', in W. Sinnott-Armstrong et al. (eds.), Modality, Morality, and Belief (Cambridge: Cambridge University Press), pp. 53-73

Geach, Peter T. 1956. 'Good and Evil', in S. M. Cahn and J. G. Haber (eds.), 20

Century Ethical Theory (Upper Saddle River, NJ: Prentice Hall), pp. 300-306 Gorman, Michael. 2005. 'The Essential and the Accidental', Ratio, 18: 276-289

${ }^{10}$ I am grateful to Jared Brandt, Rob Elisher, Gideon Jeffrey, Matt Wilson, and the participants of the conference Analytic Theology: Faith, Knowledge, and the Trinity held in Prague on 19-20 September 2013, for a number of comments on an earlier version that have greatly improved this work. The Prague conference was generously funded by the John Templeton Foundation (grant \#15571). 
Jeffrey, Gideon. 2014. 'Property Borrowing and Compositional Christology', Society of Christian Philosophers Midwest Regional Conference (Palos Heights, IL) March 27, 2014

Leftow, Brian. 2002. 'A Timeless God Incarnate', in S. T. Davis, et al. (eds.), The Incarnation: An Interdisciplinary Symposium on the Incarnation of the Son of God (Oxford: Oxford University Press), pp. 273-302

Morris, Thomas V. 1987. The Logic of God Incarnate (Ithaca: Cornell University Press)

Oppy, Graham. 2003. 'The Devilish Complexities of Divine Simplicity', Philo, 6: $10-22$

Pawl, Timothy. 2015. 'Temporary Intrinsics and Christological Predication', in J. Kvanvig (ed.), Oxford Studies in Philosophy of Religion (Oxford: Oxford University Press)

Pruss, Alexander R. Forthcoming. 'Aristotelian Forms and Laws of Nature', Analysis and Existence

Pruss, Alexander R. 2008. 'On Two Problems of Divine Simplicity', in J. Kvanvig (ed.), Oxford Studies in Philosophy of Religion, Vol. 1 (Oxford: Oxford University Press), pp. 150-167

Sider, Theodore. 2011. Writing the Book of the World (Oxford: Clarendon)

Stump, Eleonore. 'Aquinas' Metaphysics of the Incarnation', in S. T. Davis, et al. (eds.), The Incarnation: An Interdisciplinary Symposium on the Incarnation of the Son of God (Oxford: Oxford University Press), pp. 197-218

van Inwagen, Peter. 1995. 'And Yet They Are Not Three Gods But One God', in God, Knowledge, and Mystery (Ithaca: Cornell University Press), pp. 222-259 